\title{
Litera Azul: Protótipo de software de apoio à alfabetização de autistas
}

\author{
Gabriel da Silva Martins ${ }^{1}$, Jamilli dos Santos Doumany ${ }^{1}$, Elza Moura Uchoa ${ }^{1}$, \\ Josielson da Silva Arrelias ${ }^{1}$, Ederson Wilcker Figueiredo Leite ${ }^{2}$ \\ ${ }^{1}$ Acadêmicos de Licenciatura em Informática - Instituto Federal de Ciência, Educação \\ e Tecnologia do Amapá - IFAP \\ ${ }^{2}$ Prof. Msc. Orientador - Instituto Federal de Ciência, Educação e Tecnologia do \\ Amapá - IFAP \\ bsgabrielsilva@outlook.com, jamilli-doumany@bol.com.br, \\ \{uchoa.moura, proarrelias\}@gmail.com, ederson.leite@ifap.edu.br
}

Resumo. Tecnologias Assistivas são ferramentas desenvolvidas para proporcionar à pessoa com deficiência maior independência, qualidade de vida e inclusão social. Visam a ampliação de sua comunicação, mobilidade, controle de seu ambiente e habilidades de aprendizado e trabalho. Com utilização do HTML5, os integrantes deste projeto desenvolveram um software de leitura, com um banco de dados em áudio e imagens, que possui estórias de domínio público e o alfabeto ilustrado com imagens reais, ambos adaptados para reprodução em vídeo, com a finalidade de auxiliar na alfabetização $e$ entreter uma criança de 8 (oito) anos diagnosticada com autismo, nosso indivíduo alvo.

\section{Cenário de uso}

A inserção de alunos com deficiência na educação básica aumentou consideravelmente, tornando as Tecnologias Assistivas (TA) uma fonte de estímulo para a aprendizagem deste público, contribuindo para a ampliação do conhecimento, além de facilitar e enriquecer o processo ensino e aprendizagem. Tais tecnologias disponibilizam a comunidade escolar um conjunto de recursos e metodologias inovadoras para a utilização de indivíduos com alguma limitação física e/ou mental, desde as mais moderadas, até as mais graves.

O autismo é uma desordem global do desenvolvimento neurológico, definida por alterações presentes desde idades muito precoces, principalmente a partir dos três anos e que se caracteriza sempre por desvios qualitativos na comunicação, na interação social e no uso da imaginação (SILVA e BERTOSO, 2015). Segundo Junior e Ribeiro (2010), através de uma estimativa realizada pelo Instituto de Psiquiatria do Hospital das Clínicas da USP em 2007, um a cada 190 (cento e noventa) habitantes é portador do Espectro Autista no Brasil.

Mediante desafio proposto na disciplina de Tecnologias Assistivas do curso superior de Licenciatura em Informática do Instituto Federal de Educação, Ciência e Tecnologia do Amapá - IFAP, para desenvolver uma TA que desse suporte a um 
portador de necessidade especial, promovendo uma melhoria na qualidade de vida para o indivíduo, encontrou-se o sujeito desta pesquisa com acompanhamento e permissibilidade do seu responsável. Uma criança autista de 8 (oito) anos, que não conseguiu acompanhar o ritmo de alfabetização das outras crianças em mesma idade escolar, pois tem sua comunicação e socialização prejudicadas pela síndrome.

Cientes que indivíduos com autismo possuem prejuízos qualitativos em suas aptidões coletivas e comunicativas, resultando em características como impulsividade, desatenção e crises de humor, e que crianças com esta perturbação podem prescindir das outras crianças (VILA, DIOGO e SEQUEIRA, 2009), e consequente dificuldade na interação social.

Vendo esta problemática, optamos por desenvolver um software multiplataforma que auxilie na evolução cognitiva do beneficiário, através de estórias em domínio público da literatura clássica, munidas de imagem e banco de dados em áudio, junto do alfabeto com imagens multicoloridas e reais segundo o programa TEACCH (Tratamento e Educação para Autistas e Crianças com déficits relacionados à Comunicação) recomenda, para atrair a atenção da criança portadora do espectro autista. Assim, desenvolvemos o protótipo de software multiplataforma nominado Litera Azul.

\section{Desenvolvimento}

Para o desenvolvimento da pesquisa deu-se ao aporte teórico do Programa TEACCH que utilizam a teoria Behaviorista e a Psicolinguística, no qual se deve prezar pelas descrições das condutas e pela utilização de programas que usam sequências lógicas e de rotinas reforçadoras, permitindo evidenciar as características comportamentais do autista. Por outro lado, foi na psicolinguística que se buscou as estratégias para compensar os déficits comunicativos do portador do espectro autista, como a utilização de recursos visuais, tendo em vista que naturalmente estes facilitam a interação entre pensamento e linguagem, do mesmo modo que ampliam as capacidades de compreensão, onde a imagem visual é geradora de comunicação. Utilizando esta estratégia como elo entre os ambientes, autista e não-autista, para ajudar o indivíduo a entender seu ambiente cultural. Assim, a teoria comportamental e a psicolinguística bases epistemológicas do TEACCH - convergem para uma prática funcional e pragmática. (ATHERINO, KWEE e SAMPAIO, 2009, p. 318-319).

Concordando com Mello (2007), o programa TEACCH se baseia na organização do ambiente físico através de rotinas estruturadas e sistemas de trabalho, de forma a adaptar o ambiente para tornar mais fácil para a criança compreendê-lo, assim como compreender o que se espera dela. Através da organização do ambiente e das tarefas da criança, o TEACCH visa desenvolver a independência da criança de modo que ela necessite do professor para o aprendizado, mas que possa também passar grande parte de seu tempo ocupando-se de forma independente.

A metodologia de aplicação utilizada no TEACCH permite uma clareza visual ao processo de aprendizado buscando a receptividade, a compreensão, a organização e a independência. A criança trabalha num ambiente altamente estruturado que deve incluir organização física dos móveis, áreas de atividades claramente identificadas, murais de rotina e trabalhos baseados em figuras e instruções claras de encaminhamento (VATAVUK, 2005). 
Recursos visuais auxiliam o autista a compreender e interpretar a cultura na qual está inserido, e deixá-lo em contato com imagens reais e estórias que lhe façam relacionar e assimilar o nome de objetos, alimentos, animais e até mesmo os valores universais, como cooperação e responsabilidade, o ajudam a desenvolver o raciocínio lógico.

As imagens utilizadas para ilustrar o alfabeto inserido no aplicativo Litera Azul são reais e fazem parte do cotidiano do sujeito da pesquisa para o qual ele foi criado. Baseados nos princípios de Vatavuk (2005) e Melo (2007) buscou-se auxiliar na alfabetização através do recurso visual, aliando o uso de recursos de áudio, proporcionando uma maior assimilação e compreensão da realidade que o cerca.

Durante a realização da pesquisa objetivando a escolha do ambiente de desenvolvimento e a linguagem de programação em que codificaríamos o aplicativo, nos deparamos com a portabilidade na execução entre sistemas operacionais desktop e móveis que é oferecida pela linguagem de programação HTML5, em conjunto com sua vasta biblioteca de API's (Interface de programação de aplicação) que transformaram o processo de construção do aplicativo mais simples e eficaz. Utilizando uma IDE (ambiente integrado de desenvolvimento) desenvolvida pela empresa Intel (2016), o Intel XDK que usa recursos que possibilitam o desenvolvimento de softwares em HTML5 para os mais conhecidos e utilizados sistemas operacionais da atualidade, direcionamos nossos esforços para que o Litera Azul funcionasse nos dispositivos Android e Windows Phone mais atuais, e para os computadores com sistemas operacionais Windows 8 e posteriores.

\section{Apresentação do Software}

O protótipo de aplicativo proposto tem como objetivo auxiliar no processo de alfabetização de crianças autistas entre 6 (seis) a 10 (dez) anos de idade, utilizando fábulas da literatura clássica como ferramentas de apoio, compondo assim um leitor interativo utilizando recursos de áudio e imagens para atrair a atenção da criança.

Outra ferramenta de alfabetização empregada no aplicativo é um alfabeto interativo, onde as letras e objetos são mostrados através de imagens e acompanhados de áudio para que as crianças tenham mais êxito em seu aprendizado, tendo em mente que quando utilizamos figuras e sons, acabamos por deixar o ambiente mais agradável para elas.

Todo o layout do aplicativo foi desenvolvido para atrair a atenção da criança autista, focando na utilização de cores agradáveis e fortes, deixando o ambiente desenvolvido mais colorido. Além disso, os botões e o cardápio de seleção de estórias foram organizados para que a criança ao executar o aplicativo em um computador, smartphone ou tablete, possa usufruir de seus recursos com autonomia, sem precisar da ajuda de um adulto.

\subsection{Funcionamento}

Apesar de estarmos no inicio deste projeto, o processo de desenvolvimento do aplicativo já se encontra em fase avançada, pois a construção de todo seu layout já está completa, passando agora apenas por testes de compatibilidade. A página inicial do 
V Congresso Brasileiro de Informática na Educação (CBIE 2016)

Anais dos Workshops do V Congresso Brasileiro de Informática na Educação (CBIE 2016)

Litera Azul, sendo executada em um computador com o sistema Windows 8.1, é mostrada na figura 1 .

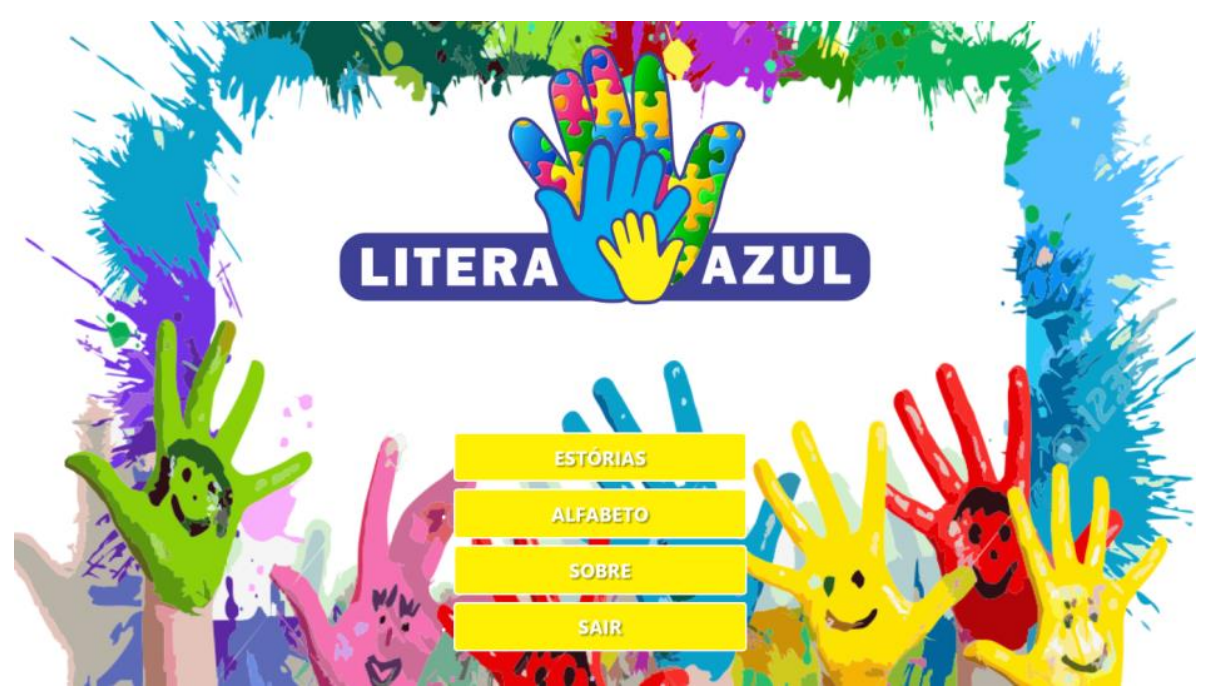

Figura 1: Página principal do Litera Azul

Para os testes iniciais, selecionamos quatro fábulas de Esopo, um grande filósofo grego (620-560 A.C.), pois ambas as estórias, passam valores e virtudes para a tentativa de trabalhar a inteligência social e emocional, sendo ótimas ferramentas de apoio à alfabetização, onde contribuem para a formação intelectual da criança.

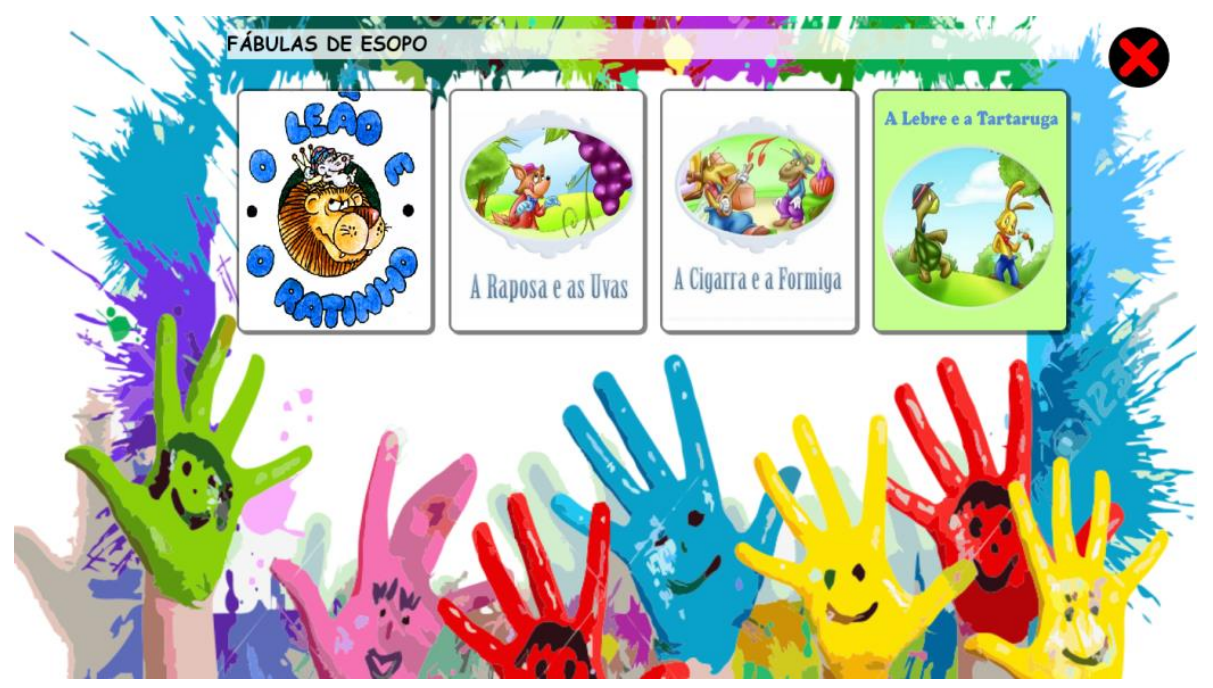

Figura 2: Página de seleção de estórias

Enquanto na página de leitura do aplicativo, utilizamos os recursos de imagem com legendas fixadas, como mostra a figura 3, e o apoio em áudio, para que mesmo que a criança autista ainda não consiga efetuar a leitura, ela possa fazer analogia do que ouve com o que vê, ou seja, ela terá o contato com o mundo letrado, para construção de sua linguagem e escrita. Esta metodologia também foi adotada no alfabeto interativo. 
V Congresso Brasileiro de Informática na Educação (CBIE 2016)

Anais dos Workshops do V Congresso Brasileiro de Informática na Educação (CBIE 2016)

Todavia, utilizamos como recurso em vídeo anexado ao aplicativo para garantir a execução direta e fixar a atenção da criança, mostrado na figura 4. Além disso, utilizamos imagens reais do cotidiano (ou provável) da criança, como é recomendado pelo programa TEACCH.

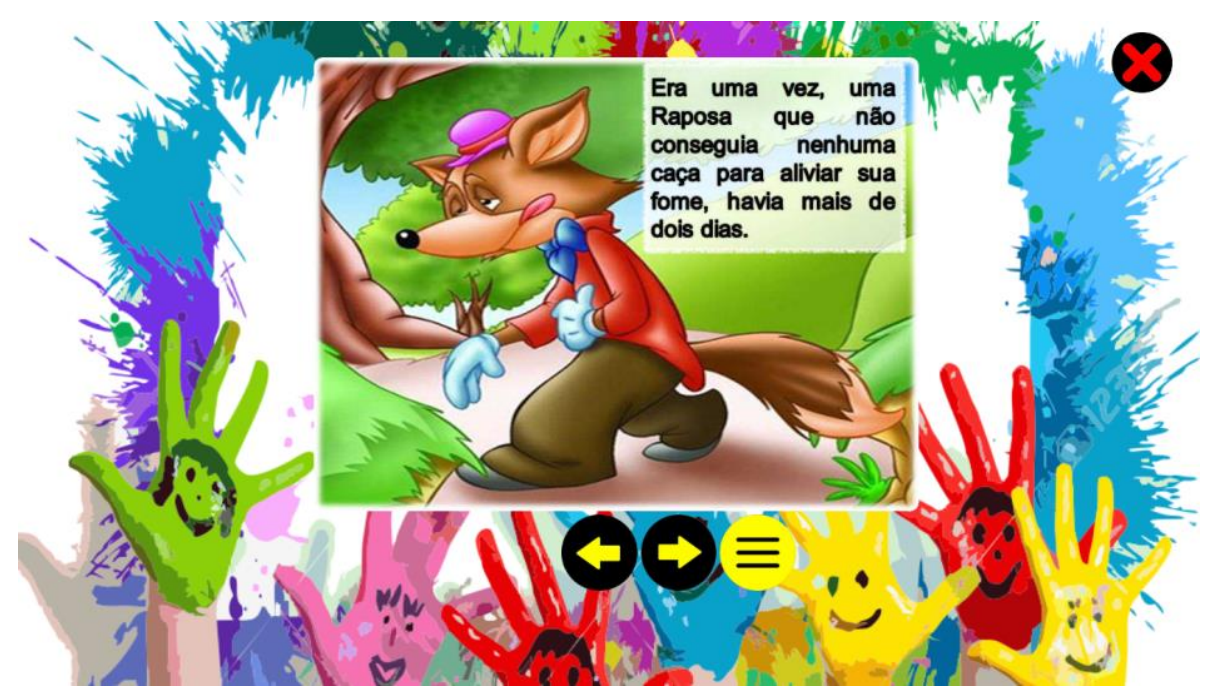

Figura 2: Página de leitura do Litera Azul

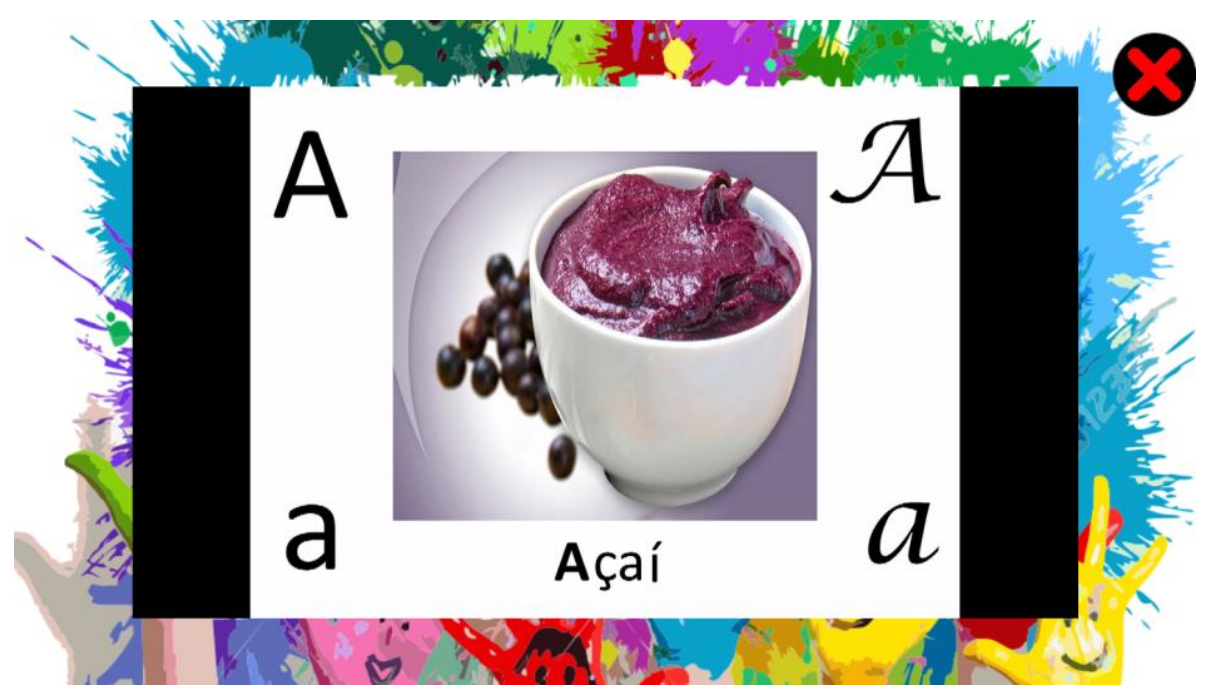

Figura 4: Página do alfabeto interativo em vídeo

\section{Considerações Finais}

Inicialmente, o desenvolvimento deste protótipo é direcionado a um único individuo, apresentado no item 1. Todavia, mesmo direcionando o aplicativo para um beneficiário específico, nota-se a possibilidade de universalizar as metodologias empregadas a partir dos testes iniciais de forma experimental. 
V Congresso Brasileiro de Informática na Educação (CBIE 2016)

Anais dos Workshops do V Congresso Brasileiro de Informática na Educação (CBIE 2016)

As funcionalidades e objetos empregados no aplicativo ainda estão em fase de testes, onde estamos avaliando a possibilidade de acrescentar novas opções ao cardápio, como por exemplo, jogos e atividades para colorir, entretanto, o alfabeto interativo em vídeo baseado no método TEACCH, é um importante objeto a ser mantido no aplicativo, outrora, aperfeiçoado e melhorado.

Dessa forma, visamos adicionar novas estórias, que ensinem valores e virtudes que possam auxiliar na construção da inteligência social e emocional da criança, além de expandir nosso público, levando a outras crianças com o mesmo problema. Visamos assim, a melhoria dos recursos inclusos no aplicativo, melhorando o desempenho na execução, sua qualidade de áudios, adicionando outros recursos que possam contribuir mais ainda para o auxilio na alfabetização.

\section{Referências}

Bertoso, E. B. F., Silva, A. F. (2015) O autismo e o professor. http://www.psicopedagogia.com.br/new1_artigo.asp?entrID=1819\#.V0jDfFKNFXQ, Maio 2016.

Intel. (2016) Documentação para suporte Intel XDK. Intel Developer Zone. https://software.intel.com/pt-br/intel-xdk-support/documentation, Março 2016

Schmitt, C. (2011) HTML5 Cookbook, O’Reilly Media.

Weyl, Estelle. (2014) Mobile HTML5, Novatec Editora.

Kwee C.S., Sampaio T.M.M., Atherino C.C.T. (2009) autismo: Uma avaliação transdisciplinar baseada no programa TEACCH. Revista CEFAC, v.11, Supl2, p. 217-226.

Nova, N. T. V.(2010) O olhar sensibilizador da psicopedagogia no processo de aprendizagem do autista na escola inclusiva. Universidade do Rio de Janeiro: $\begin{array}{lllll}\text { Instituto } & \mathrm{a} & \mathrm{Vez} & \text { Mestre. }\end{array}$ http://www.avm.edu.br/docpdf/monografias_publicadas/c205709.pdf, Maio 2016.

Vila, C. Diogo, S. Sequeira, S. (2015) Autismo e síndrome de asperger. http://atividadeparaeducacaoespecial.com/wp-content/uploads/2015/08/psicologiakaner-e-asperger.pdf, Maio 2016. 